\title{
Uma Pletora de Poliedros e a Metodologia da Engenharia Didática: potencializando o ensino de Poliedros Regulares
}

\section{Rafaela Moraes Cruz}

Universidade Federal Fluminense

rafaela.cruz@iff.edu.br

\section{Marcelo de Oliveira Dias}

Universidade Federal Fluminense

marcelo_dias@id.uff.br

\section{Resumo}

O presente artigo apresenta parte dos resultados de uma investigação realizada no contexto do Programa de Pós Graduação em Ensino da Universidade Federal Fluminense (UFF), no Instituto do Noroeste Fluminense de Educação Superior (INFES), que teve por objetivo identificar as contribuições do software Uma Pletora de Poliedros para o ensino de Poliedros Regulares. Para a realização deste estudo foi utilizada a Engenharia Didática como metodologia de pesquisa, na qual houve reflexões da professora/pesquisadora nas quatro fases propostas por essa metodologia. A sessão de ensino planejada a partir da Engenharia Didática contou com uma amostra de 53 estudantes da $1^{\text {a }}$ série do Curso Técnico Integrado ao Ensino Médio do Campus Santo Antônio de Pádua do IFFluminense. Dessa análise, destacamos que, dentre as considerações conclusivas, a visualização espacial potencializada pelo software e a dinamicidade do processo de ensino contribuíram para a apropriação do conteúdo Poliedros Regulares.

Palavras-chave: Softwares. Geometria Dinâmica. Geometria Espacial.

\section{A Plethora of Polyhedra and the Methodology of Didactical Engineering: enhancing the teaching of Regular Polyhedra}

\begin{abstract}
This article puts forward part of the results of an investigation held in the environment of the Educational Post-Graduation Program at Universidade Federal Fluminense (UFF), at the Instituto do Noroeste Fluminense de Educação Superior (INFES), that aimed to identify the contributions of the software Uma Pletora de Poliedros ("A Plethora of Polyhedra") for teaching Regular Polyhedra. For the accomplishment of this survey, the Didactical Engineering was used as a method of research, in which there were thoughts of the teacher/researcher's in the four stages proposed by the methodology. The teaching session planned from the Didactical Engineering relied on the sample of 53 students from the $1^{\text {st }}$ grade at the Ensino Técnico Integrado ao Ensino Médio from IFFluminense Campus Santo Antônio de Pádua. On the basis of this analysis, it may be highlighted that, among the conclusive considerations, the spatial view enhanced by the software and the dynamism of the teaching process have contributed for the appropriation of the Regular Polyhedra content.
\end{abstract}

Keywords: Softwares. Dynamic Geometry. Space Geometry. 


\section{Introdução}

As situações didáticas em Matemática, em especial da Geometria, comumente vem sendo marcadas por dificuldades no processo de ensino e aprendizagem. Resende e Mesquita (2013, p. 201) afirmam que "dificuldades no processo ensino-aprendizagem de Matemática existem e conforme relatadas na literatura devem ser sempre questionadas e analisadas objetivando sempre a otimização no processo".

Dessa forma, a utilização de recursos didáticos que potencializem o processo educacional pode aumentar as possibilidades de uma aprendizagem significativa. Nesse rol, têm-se os softwares educacionais de Geometria Dinâmica, que, segundo Almeida (2010, p. 46), são

softwares interativos que permitem a criação e manipulação direta de figuras geométricas a partir de suas propriedades. Assim, vemos emergir uma maneira de ensinar e aprender geometria, a partir da exploração experimental que possibilita a passagem de uma figura à outra pelo deslocamento quase contínuo dos elementos, viável apenas em ambientes dinâmicos.

O conteúdo Poliedros Regulares, pertencente ao currículo proposto para a Geometria Espacial, pode ter seu ensino potencializado com a utilização de softwares educacionais. A visualização disponível nos softwares de Geometria Dinâmica, por exemplo, pode auxiliar na compreensão do objeto de estudo. Segundo Veloso (1998) ${ }^{1}$ apud Lemos e Bairral (2010, p. 73),

o desenvolvimento da capacidade de visualização, em particular no espaço tridimensional, deve ser um dos primeiros objetivos do ensino de geometria. Essa capacidade necessita ser apoiada com diversos tipos de recursos didáticos e representações, pois cada um contribui diferentemente no processo de desenvolvimento conceitual.

Assim, o software Uma Pletora de Poliedros (Figura 1), que segundo Bortolossi (2009) é "um software interativo que permite a visualização e manipulação de vários tipos de poliedros" e que possui como objetivo "exercitar visualização espacial; identificar, comparar e analisar atributos geométricos e topológicos dos poliedros" pode ser utilizado como recurso didático para o ensino de Poliedros Regulares.

Figura 1 - Interface do software Uma Pletora de Poliedros

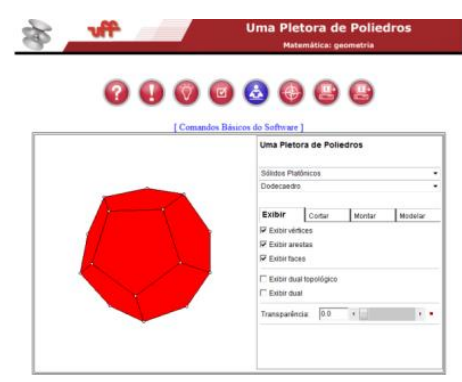

Fonte - http://www.uff.br/cdme/pdp/.

\footnotetext{
${ }^{1}$ VELOSO, E. Geometria: temas actuais: materiais para professores. Lisboa: IIE, 1998.
} 
Logo, este estudo buscou responder como a Pletora de Poliedros, como recurso didático em uma sessão de ensino, pode contribuir para o ensino e aprendizagem de Poliedros Regulares a alunos da $1^{\mathrm{a}}$ série de Curso Técnico Integrado ao Ensino Médio do Campus Santo Antônio de Pádua do IFFluminense.

\section{Revisão de Literatura}

Com o intuito de dinamizar o processo educativo, a escola tem incluído os recursos tecnológicos nas práticas pedagógicas. A tecnologia, além de ser familiar aos estudantes, pode ser utilizada no ensino de conceitos específicos, por meio de práticas docentes mais atualizadas e com uso pedagógico adequado.

Dentre os conhecimentos que podem ser explorados com o auxílio de recursos tecnológicos tem-se a Matemática. Segundo as Orientações Curriculares Nacionais para o Ensino Médio (OCNEM), a tecnologia faz parte da sociedade e esta pode contribuir com a aprendizagem matemática.

Não se pode negar o impacto provocado pela tecnologia de informação e comunicação na configuração da sociedade atual. Por um lado, tem-se a inserção dessa tecnologia no dia a dia da sociedade, a exigir indivíduos com capacitação para bem usá-la; por outro lado, tem-se nessa mesma tecnologia um recurso que pode subsidiar o processo de aprendizagem da Matemática. (BRASIL, 2006, p. 87)

Nesse viés, para que a tecnologia esteja presente no ensino de Matemática, fazem-se necessárias posturas pedagógicas que utilizem diversas ferramentas que possam provocar o aprendizado. Borba e Penteado (2012, p. 88) direcionam o trabalho docente para "propostas pedagógicas que enfatizem a experimentação, visualização, simulação, comunicação eletrônica e problemas abertos".

Como parte da prática docente, tem-se a definição da mídia a ser utilizada para o ensino de determinado conteúdo. Borba e Penteado (2012) explicam que o professor deve avaliar o que se quer enfatizar com os alunos e qual mídia poderá atender adequadamente o propósito de ensino. Os autores afirmam que,

quando decidimos que a tecnologia informática vai ser incorporada em nossas práticas, temos que, necessariamente, rever a relevância da utilização de tudo o mais que se encontra disponível. Certamente, ao fazermos nossas opções, corremos o risco de deixar de lado certas coisas que julgávamos importante. Mas, aqui, novamente, é preciso considerar qual é o objetivo da atividade que queremos realizar e saber se ela não pode ser desenvolvida com maior qualidade pelo uso, por exemplo, de um software específico. Não significa que vamos abandonar as outras mídias, mas temos que refletir sobre sua adequação. (BORBA; PENTEADO, 2012, p. 64) 
Nesse sentido, para o ensino de Geometria, um dos eixos da Matemática, os softwares de Geometria Dinâmica podem contribuir para o ensino de múltiplos conteúdos. Para a escolha adequada do software o professor deve considerar a abordagem que seus recursos possibilitam para cada conteúdo específico, como indicam as OCNEM.

No uso de tecnologia para o aprendizado da Matemática, a escolha de um programa torna-se um fator que determina a qualidade do aprendizado. É com a utilização de programas que oferecem recursos para a exploração de conceitos e ideias matemáticas que está se fazendo um interessante uso de tecnologia para o ensino da Matemática. (BRASIL, 2006, p. 89-90)

Os softwares de Geometria Dinâmica possibilitam as visualizações gráficas dos objetos de estudos, recursos que podem auxiliar na compreensão de definições e contribuir para o desenvolvimento da aprendizagem, pois, como afirma Lima (2010, p. 27), “a visualização é considerada necessária para a aprendizagem de matemática”.

Ainda sobre a importância da visualização, os autores Lemos e Bairral (2010, p. 74) sinalizam que "a representação mental dos objetos geométricos, a análise e a organização formal das propriedades geométricas relativas a um conceito geométrico são passos preparatórios para o entendimento da formalização de um conceito".

Contudo, mesmo diante da disponibilidade de recursos tecnológicos que podem auxiliar o processo educativo, há inseguranças em sua utilização no ensino. As mudanças que tendem a ser geradas pelo uso da tecnologia em sala de aula podem gerar desconfortos para os professores adotarem esses recursos. Os autores Borba e Penteado (2012) descrevem a existência de uma zona de risco, na qual o uso da tecnologia no ensino, como uma situação de risco, altera a dinâmica da sala de aula, pois gera a possibilidade de decorrência de problemas técnicos e de perguntas imprevisíveis.

Contudo, a zona de risco pode ser considerada como desencadeadora de novas possibilidades para o desenvolvimento profissional do docente, uma vez que ela desafia o professor a novas práticas. Na concepção de Borba e Penteado (2012, p. 66) identifica-se que "é difícil negar o potencial que uma zona de risco tem de provocar mudanças e impulsionar desenvolvimento".

Além disso, Miskulin e Viol (2014, p. 1313) afirmam que

os educadores, precisam estar abertos às novas formas do saber humano, novas maneiras de gerar e dominar o conhecimento, novas formas de produção e apropriação do conhecimento da prática docente, isto se não quiserem ficar estagnados em métodos de ensino e teorias de trabalhos obsoletos.

Assim, práticas pedagógicas alternativas podem contribuir para o ensino e aprendizagem de Matemática. De modo mais específico, têm-se os softwares de Geometria Dinâmica para o 
estudo dos conteúdos geométricos, que disponibilizam recursos que auxiliam a compreensão da Geometria, seja ela Plana ou Espacial.

\section{Procedimentos Metodológicos}

Para esta investigação, na qual se adotou o software Uma Pletora de Poliedros como recurso didático, utilizou-se como metodologia de pesquisa a Engenharia Didática, desenvolvida por Artigue (1988) para observar e analisar situações didáticas. Esta metodologia conta com quatro fases: análises preliminares, concepção e análise a priori, experimentação e análise a posteriori e validação.

$\mathrm{Na}$ fase das análises preliminares, foram realizados os estudos prévios em torno dos Poliedros Regulares. Na dimensão epistemológica, foi investigada a definição dos Poliedros Regulares, a Relação de Euler, os processos de dualidade, truncamento e planificação e sua relação com os elementos dos sólidos: vértices, arestas e faces.

Buscou-se também a relação do conteúdo com diferentes áreas do conhecimento, e, a partir de então, identificou-se que os Poliedros Regulares podem ser integrados à Filosofia, Física e Biologia. Somado a essas integrações, têm-se os Poliedros Regulares articulados com o cotidiano do estudante por meio da bola de futebol, que se trata de um icosaedro truncado.

$\mathrm{Na}$ análise da dimensão didática, foi realizado um estudo sobre a abordagem do conteúdo no livro didático disponível para os estudantes participantes da pesquisa. Identificou-se que a coleção de Ensino Médio "Matemática: ciência e aplicações" do Programa Nacional do Livro Didático - 2012 - não explora os cinco poliedros regulares, mas apenas o cubo e tetraedro, além de não explorar a Relação de Euler. Diante disso, optou-se por elaborar, para os alunos, um material complementar que abordasse o conteúdo e os processos de truncamento, dualidade e planificação desses sólidos.

Para realização da análise cognitiva foi promovido um primeiro encontro com os estudantes, com o fim de buscar, por meio de uma atividade diagnóstica, os conhecimentos prévios dos estudantes acerca do conteúdo. Nesse encontro contou-se com a participação de 40 alunos, distribuídos entre as turmas C e D, da $1^{\mathrm{a}}$ série do Curso Técnico Integrado ao Ensino Médio.

Com a atividade diagnóstica aplicada, identificou-se que a maioria dos estudantes conhecem as figuras planas: o triângulo, quadrado e o pentágono (polígonos que são faces dos poliedros regulares). Porém, nenhum dos estudantes identificou corretamente a nomenclatura dos poliedros regulares: octaedro e icosaedro.

Além disso, 23 dos 40 alunos apresentaram dificuldades em verificar a Relação de Euler para o octaedro, enquanto apenas 17 deles verificaram corretamente a relação. $\mathrm{Na}$ análise realizada 
sobre a atividade foi possível observar possíveis entraves algébricos e geométricos sobre o conteúdo. Assim, inferiu-se que seria possível a construção de um panorama que pudesse ser adequado para o estudo de Poliedros Regulares. Para tanto, propôs-se o uso do software Uma Pletora de Poliedros como ferramenta de apoio ao ensino do conteúdo proposto.

$\mathrm{Na}$ fase de concepção e análise a priori da Engenharia Didática foram definidas as variáveis macrodidáticas, que se referem à organização global da Engenharia, e as variáveis microdidáticas que concernem à organização de uma sessão de ensino (ARTIGUE, 1988).

As variáveis macrodidáticas definidas nesta pesquisa foram: enfatizar o quadro geométrico do estudo de Poliedros Regulares; estudar os Poliedros Regulares com possíveis integrações de diferentes áreas e contextualização; utilizar computador e o software Uma Pletora de Poliedros; definir os cinco poliedros regulares e investigar suas características por meio dos recursos de movimento do software; compreender a relação de Euler; valorizar a validação dos conceitos por parte dos alunos; e aliar papel e computador no estudo e resolução de atividades, baseado em definições disponíveis no software e em material complementar.

A partir dessas variáveis, escolheram-se as variáveis microdidáticas, que podem ser descritas como: realizar uma sessão de ensino com duas turmas de estudantes, em duas horas de aula por turma; utilizar o laboratório de informática da escola participante; explorar o software em conjuntos de alunos devido à quantidade de computadores disponíveis; incentivar, entre os alunos, a socialização das experiências com o software; aplicar atividades que provoquem o uso do software para resolução; e disponibilizar material para construção de um poliedro regular como atividade de casa.

As hipóteses que estiveram em jogo na validação da Engenharia Didática concebida foram definidas na análise a priori. Assim, pressupôs-se que: os alunos iriam adquirir conhecimento sobre o conteúdo proposto; com a utilização do software Uma Pletora de Poliedros no processo de ensino, os conhecimentos seriam aprendidos com maior dinamicidade; e as dificuldades que poderiam surgir devido ao compartilhamento da exploração do software seriam superadas com a socialização do conhecimento entre os alunos.

A fase de experimentação foi realizada no segundo encontro, com uma amostra de 53 estudantes presentes. A sessão de ensino, conforme definido nas variáveis microdidáticas, foi realizada no laboratório da escola, em duas horas/aulas por turma, com duas turmas.

No início da sessão de ensino os alunos foram orientados que o computador seria usado por dois ou três estudantes; que o conteúdo seria estudado com o uso do software; que o material complementar, que continha o conteúdo proposto, poderia ser consultado a qualquer tempo; que os conhecimentos poderiam ser socializados entre os alunos de forma a ajudar os colegas; que a 
atividade deveria ser realizada junto ao software; que a atividade deveria ser respondida individualmente; e que a professora/pesquisadora estaria à disposição para auxiliá-los em relação às dúvidas interpretativas e algébricas, mas sem intervir nas descrições das resoluções.

Em seguida, foram exploradas junto aos alunos as possíveis integrações dos poliedros regulares com a Filosofia, Física e Biologia. Foi trabalhado também com os alunos a origem e significado da palavra poliedro.

Adiante, os estudos foram realizados a partir do software. Com o auxílio do botão de definições disponível no software, bem como do material complementar e, ainda, do quadro branco, estudaram-se as definições de Poliedros, Poliedros Convexos e Poliedros Regulares. Somada às definições, foi apresentada aos alunos a propriedade dos Poliedros Regulares: existem cinco, e somente cinco Poliedros de Platão.

A partir de então, os estudantes visualizaram no software os cinco Poliedros Regulares e estudaram seus elementos por meio dos recursos de exibição individual ou conjunta dos elementos dos Poliedros: vértices, arestas e faces; a transparência para visualizar o interior do poliedro, permitindo a contagem dos elementos; e o clique com o botão esquerdo, com o arraste do mouse para girar os sólidos. Para realização da atividade, esses recursos puderam ser utilizados.

Em seguida, explicou-se aos alunos a relação de Euler por meio da resolução de um exercício no quadro branco. A dualidade dos Poliedros foi apresentada por meio do software, quando foi possível visualizar e explorar o procedimento de dualidade com cada um dos cinco Poliedros Regulares.

Foi abordado também o processo de truncamento dos Poliedros Regulares, em especial o icosaedro truncado que se refere à estrutura da bola de futebol. No software, o processo foi explorado pelo recurso próprio de truncar e por meio do uso dos recursos de transparência e da visualização do corte simétrico dos poliedros a partir dos vértices por meio do recurso de corte por seção, que deu maior ilustratividade ao processo.

Em seguida, foi exibido o processo de planificação dos Poliedros Regulares e explorou-se o recurso que disponibiliza o molde para construção do poliedro selecionado. Finalizada a atividade realizada durante o estudo do conteúdo, foi recomendado aos estudantes que realizassem a construção de um Poliedro Regular, como atividade de casa, para que tivessem a oportunidade de manusear o objeto de estudo com autonomia. Para esta atividade, distribuíram-se papel cartão e o molde do poliedro escolhido pelo aluno. Em momento posterior, as construções foram recolhidas e registradas.

Na fase de análise a posteriori e validação foi realizada a análise dos dados colhidos na experimentação para, a partir de então, validar ou não a Engenharia concebida. Assim, as repostas 
da atividade aplicada durante a sessão de ensino foram analisadas e confrontadas com as dificuldades e dúvidas apresentadas pelos estudantes.

Com a intenção de instigar os estudantes a explorarem, por meio da visualização, a nomenclatura e os elementos dos Poliedros Regulares, foi proposta a primeira questão da atividade. $\mathrm{Na}$ resolução, foi verificado que alguns alunos utilizaram o software e seus recursos de transparência e exibição dos elementos para contagem dos elementos por meio da visualização tridimensional do objeto. Do total de estudantes, 39 preferiram resolver a questão utilizando somente a relação de Euler ou a usaram para conferir a contagem feita inicialmente pelo software, como se vê na Figura 2.

Figura 2 - Exemplo de resolução da questão $n^{0} 1$ da atividade aplicada na sessão de ensino

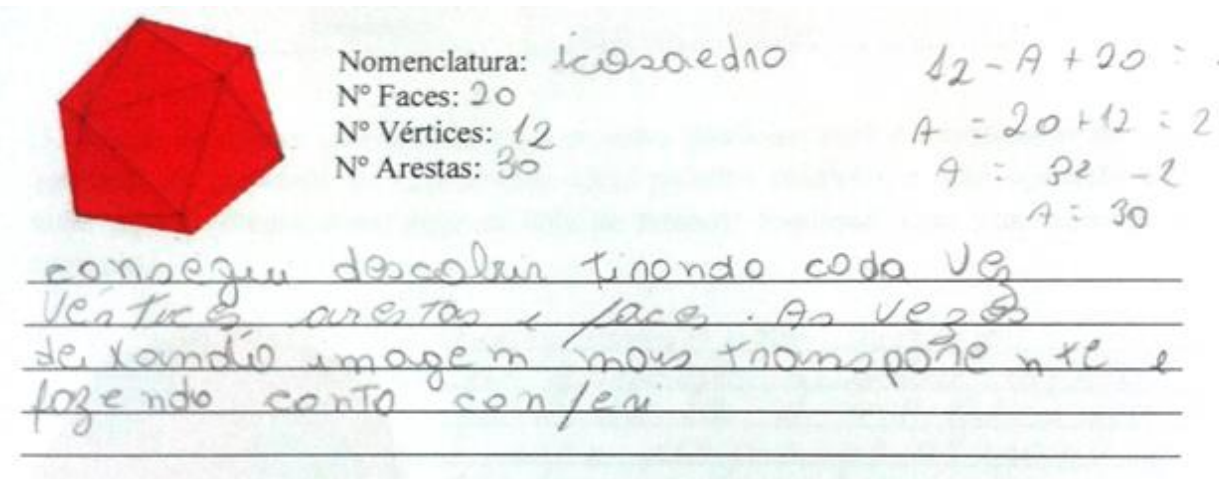

Fonte: Elaborada pelos autores.

Na segunda questão da atividade, em que o objetivo era a exploração dos elementos do poliedro regular octaedro por meio de sua planificação, notou-se que o número de faces foi contado por meio da planificação e os demais elementos, vértices e arestas, foram verificados com a relação de Euler. Apenas dois estudantes não responderam corretamente a questão, pois descreveram o poliedro dado como "tetraedro".

Na terceira questão da atividade, em que o objetivo era verificar a relação de Euler a partir de um problema, observou-se que houve, por parte dos estudantes, dificuldades de interpretação e organização das informações dadas pelo enunciado da questão. Devido a isso, a professora/pesquisadora auxiliou os estudantes com explicação para prosseguimento da atividade.

Após a explicação, identificou-se que 42 estudantes conseguiram resolver corretamente a questão, e que alguns deles utilizaram o software para auxiliar na atividade, ao explorar a tecla 9 para conferência do número de faces, vértices e arestas.

As questões quatro e seis da atividade foram elaboradas para instigar os estudantes a utilizarem o software para exploração dos duais dos Poliedros Regulares. Na realização dessas atividades, foi possível observar os alunos configurando o objeto por meio do recurso que apresenta o dual do poliedro selecionado e com o uso da transparência, bem como da rotação do poliedro. 
Identificou-se que os estudantes exploraram o poliedro original e o dual em seu interior para responder a questão quatro da atividade.

Já na sexta questão, constatou-se que a maioria dos estudantes identificou a relação entre os Poliedros Regulares originais e seus duais: o hexaedro possui o octaedro como dual, bem como o octaedro possui o hexaedro como dual; o dodecaedro possui o icosaedro como dual e o icosaedro possui o dodecaedro como dual; já o tetraedro possui ele mesmo como dual.

$\mathrm{Na}$ questão cinco, com o intuito de estudar o processo de truncamento, propôs-se a exploração do truncamento do icosaedro para obtenção da bola de futebol, que se trata de um Poliedro Arquimediano. Nesta atividade, notou-se que os estudantes conheceram e compreenderam o processo de truncamento. Foi utilizado também o recurso de corte por seção junto ao de transparência e rotação do poliedro para melhor compreensão do processo de truncamento.

Somada à análise da atividade, foi possível observar que o estudo dos Poliedros Regulares e dos processos de dualidade, corte por seção, truncamento e os Poliedros Arquimedianos, foram realizados de forma interconectada. Durante o estudo, foi identificada a apreciação, por parte dos estudantes, da interface e da variedade de recursos disponíveis no software. Porém, na exploração inicial do software, a professora/pesquisadora notou que os alunos tiveram uma pequena dificuldade oriunda de travamentos do software, o que gerou um pequeno atraso no processo de estudo.

Além da análise da atividade, buscou-se colher a opinião dos estudantes por meio registro escrito sobre o uso do software Uma Pletora de Poliedros na sessão de ensino. Assim, aplicou-se aos estudantes um questionário com duas questões abertas.

A primeira questão do questionário visou levantar a opinião dos estudantes sobre a contribuição do software Uma Pletora de Poliedros para o estudo dos Poliedros Regulares. Da análise das respostas, observou-se que muitos alunos descreveram que houve potencialização do ensino. Como exemplo, pode-se citar o registro de um dos alunos: "o uso do software para o estudo de poliedros regulares, foi, sem dúvida, muito importante para todos nós [alunos]” (AL1).

$\mathrm{Na}$ análise da segunda questão do questionário, em que o intuito era levantar a opinião dos estudantes a respeito dos recursos disponíveis no software, observou-se que muitos estudantes consideraram os recursos eficientes para a aprendizagem. Como exemplo, pode-se citar a resposta de um estudante: "todos os recursos (transparência, identificar vértices, arestas, faces, dual, etc.) nos ajudou muito, e eles são muito fáceis de mexer" (AL2).

Para acrescentar à análise da sessão de ensino, aplicou-se aos estudantes um questionário com questões fechadas. Do material colhido, no contexto da pesquisa, foi possível constatar que, do total de estudantes participantes da sessão de ensino, 40 deles consideraram que o software Uma Pletora de Poliedros contribuiu muito para a aprendizagem de Poliedros Regulares. Um aluno 
registrou no questionário aberto que: "[o uso do software] foi bom para nosso aprendizado, pois pudemos fazer coisas que não fazemos em sala de aula. [...] A tecnologia é importante para nosso aprendizado, ela nos ensina de um modo mais fácil de aprender e de uma forma diferente" (AL3).

Foi indagada também a opinião dos estudantes sobre a interação e dinâmica da aula, e observou-se que 45 estudantes consideraram o nível de interação e dinamicidade como muito ou regular. Assim, infere-se que a Pletora de Poliedros promoveu interação entre aluno e software, aluno e aluno, bem como entre aluno e professor e dinamicidade no processo de ensino e aprendizagem.

Das dificuldades que poderiam surgir decorrentes do uso compartilhado do software pelos estudantes, averiguou-se que 43 estudantes não consideraram que o estudo foi comprometido por compartilhar o software com outros colegas, e ademais notou-se que a distribuição de mais de um aluno por computador contribuiu para a socialização do conhecimento e conseguinte do aprendizado, como descreveu um aluno em resposta ao questionário de questões abertas: "[a utilização do software] me mostrou um jeito diferente de aprender, tanto no sentido da matéria, quanto na ajuda com os colegas" (AL4).

Dessa forma, verifica-se que as hipóteses previstas na análise a priori para as ações de ensino foram confirmadas no contexto em que foi aplicada a pesquisa, validando assim, a Engenharia Didática.

\section{Considerações finais}

Ao longo desta pesquisa buscou-se analisar de que forma o ensino com o auxílio do software educacional Uma Pletora de Poliedros pode contribuir para a aprendizagem do conteúdo Poliedros Regulares

Com a organização e experimentação da sequência didática observou-se que a primeira fase da Engenharia auxiliou a análise do ensino usual do conteúdo, e, a partir dela, concebeu-se na segunda fase uma sessão de ensino com o apoio do software Uma Pletora de Poliedros como recurso didático, levantando hipóteses em torno do planejamento sobre as ações em sala de aula.

$\mathrm{Na}$ terceira fase da Engenharia Didática, foi realizada a experimentação da sessão de ensino planejada. Já na quarta fase, foi realizada a análise dessa experimentação frente aos estudos preliminares, além da validação da Engenharia Didática a partir das hipóteses levantadas em sua concepção.

Com a experimentação da sequência de ensino, verificou-se a compreensão dos conceitos geométricos ensinados aos alunos, e na resolução da atividade realizada notaram-se marcas da utilização do software, expondo a contribuição deste instrumento para o processo de aprendizagem. 
A partir da experimentação, foi possível avaliar a percepção dos estudantes quanto à contribuição do software Uma Pletora de Poliedros para o desenvolvimento da aprendizagem do conteúdo Poliedros Regulares. Observou-se que o software proporcionou, tanto por meio da exploração de suas ferramentas, quanto dos recursos ilustrativos, um estudo diferenciado tendo em vista que ele proporciona a visualização espacial dos objetos de estudo, permitindo ao aluno interagir e movimentar poliedros.

Além disso, observou-se que o software foi considerado um importante instrumento didático para o ensino de Poliedros Regulares, sendo reconhecida por muitos alunos a dinamicidade do processo de aprendizagem.

Com esta pesquisa foi possível verificar também a potencialidade que a Engenharia Didática, enquanto metodologia representa para a prática docente, visto que ela se configurou como um instrumento auxiliador no planejamento da prática pedagógica, bem como na construção dos conceitos ensinados.

Por meio da análise a posteriori, houve a confirmação das hipóteses levantadas na análise a priori da Engenharia Didática, tornando possível concluir que a utilização do software Uma Pletora de Poliedros representa avanços significativos para o ensino e aprendizagem de Poliedros Regulares.

Assim, a combinação do uso de uma ferramenta tecnológica com a metodologia da Engenharia Didática proporcionou, neste estudo, a compreensão de que a tecnologia pode auxiliar na aprendizagem sem anular o esforço da atividade compreensiva, promovendo ampliação, consolidação dos conceitos e formação crítica dos educandos.

\section{Referências}

ALMEIDA, T. C. S. Sólidos Arquimedianos e Cabri 3D: um estudo de truncaturas baseadas no Renascimento, 2010. 189f. Dissertação (Mestrado Profissional em Ensino de Matemática). Pontifícia Universidade Católica de São Paulo, São Paulo, 2010. Disponível em: < http://livros01.livrosgratis.com.br/cp137922.pdf>. Acesso em: 12 jul. 2016.

ARTIGUE, M. Ingénierie Didactique. Recherches em Didactique des Mathématiques. Grenoble: La Pensée Sauvage-Éditions, v. 9.3, p. 281-3008, 1988.

BORBA, M. C.; PENTEADO, M. G. Informática e educação matemática. 5. ed. Belo Horizonte: Autêntica, 2012.

BORTOLOSSI, H. J. Uma Pletora de Poliedros. 2009. Disponível em:

<http://www.uff.br/cdme/pdp/>. Acesso em 28 mar. 2016.

BRASIL. Secretaria de Educação Básica. Orientações curriculares para o Ensino Médio. v. 2, Ciências da Natureza, Matemática e suas Tecnologias. Brasília: MEC/SEB, 2006.

LEMOS, W. G. BAIRRAL, M. A. Poliedros estrelados no currículo do Ensino Médio. Rio de Janeiro: Edur, 2010. 
LIMA, C. W. Representações dos números racionais e a medição de segmentos: possibilidades com tecnologias informáticas. 2010. 197f. Dissertação (Mestrado em Educação Matemática) Instituto de Geociências e Ciências Exatas, Universidade Estadual Paulista, Rio Claro, 2010. Disponível em:

<repositorio.unesp.br/bitstream/handle/11449/91103/lima_cw_me_rcla.pdf?sequence=1\&isAllowed =y>. Acesso em: 23 abr. 2016.

MIALICH, F. R. Poliedros e Teorema de Euler. 2013. 81f. Dissertação (Mestrado em Matemática). Universidade Estadual Paulista, São José do Rio Preto, 2013. Disponível em: $<$ http://bit.profmatsbm.org.br/xmlui/bitstream/handle/123456789/433/2011_00311_FLAVIA_RENATA_MIALICH.p df?sequence=1>. Acesso em: 08 ago. 2016.

MISKULIN, R. G. S.; VIOL, J. F. As práticas do professor que ensina matemática e suas interrelações com as tecnologias digitais. Revista e-Curriculum, São Paulo, v. 12, n. 2, p.13111330, 2014. Disponível em: 〈https://revistas.pucsp.br/index.php/curriculum/issue/view/1299>

RESENDE, G.; MESQUITA, M. G. B. F. Principais dificuldades percebidas no processo ensinoaprendizagem de matemática em escolas do município de Divinópolis, MG. Revista Educação Matemática Pesquisa, São Paulo, v. 15, n. 1, p. 199 - 222, 2013.

Submetido em janeiro de 2017 Aprovado em março de 2017 